\title{
Cetrimide burn in an infant
}

\author{
D. M. MERCER \\ M.B., Ch.B., F.R.C.S.
}

Department of Plastic Surgery, Booth Hall Children's Hospital, Charlestown Road, Manchester M9 2AA

\begin{abstract}
Summary
A case of chemical burns due to cetrimide applied to the nappy area of an infant is recorded.
\end{abstract}

KEY WORDS: cetrimide, chemical burns.

\section{Introduction}

Chemical burns in children are rare (Pegg et al., 1978; Stitz, 1972). A 3-month-old baby who sustained superficial burns to the nappy area due to a quartenary ammonium compound, cetrimide, is described.

\section{Case report}

The patient's sister had left hospital a few months earlier after sustaining a scald to the scalp which had required skin grafting. A proprietary shampoo had been recommended by a local shopkeeper to keep the scalp clean. One evening, another of the patient's siblings, her 7-year-old brother, rubbed some of this shampoo in during a nappy change. The patient was unsettled overnight, and presented the following morning with the lesions shown in Fig. 1. The lesions were treated with silver sulphadiazine cream and healed within 7 days (Fig. 2). Subsequent investigations showed that the 'shampoo' was $17 \frac{1}{2} \%$ cetrimide solution (Cetavlon).

\section{Discussion}

Chemical burns form approximately 3\% of burn injuries seen in children (Pegg et al., 1978; Stitz, 1972) and usually involve toxic gardening or cleansing solutions.

Cetavlon (Cetrimide) is a proprietary product containing a mixture of alkyl-trimethylammonium bromides (quartenary ammonium compounds) and is widely used in both hospitals and the community for its sterilizing properties, for skin antisepsis and for hair shampooing. It is available in both powder and liquid form in different concentrations, and may be purchased over the counter in most chemist shops.

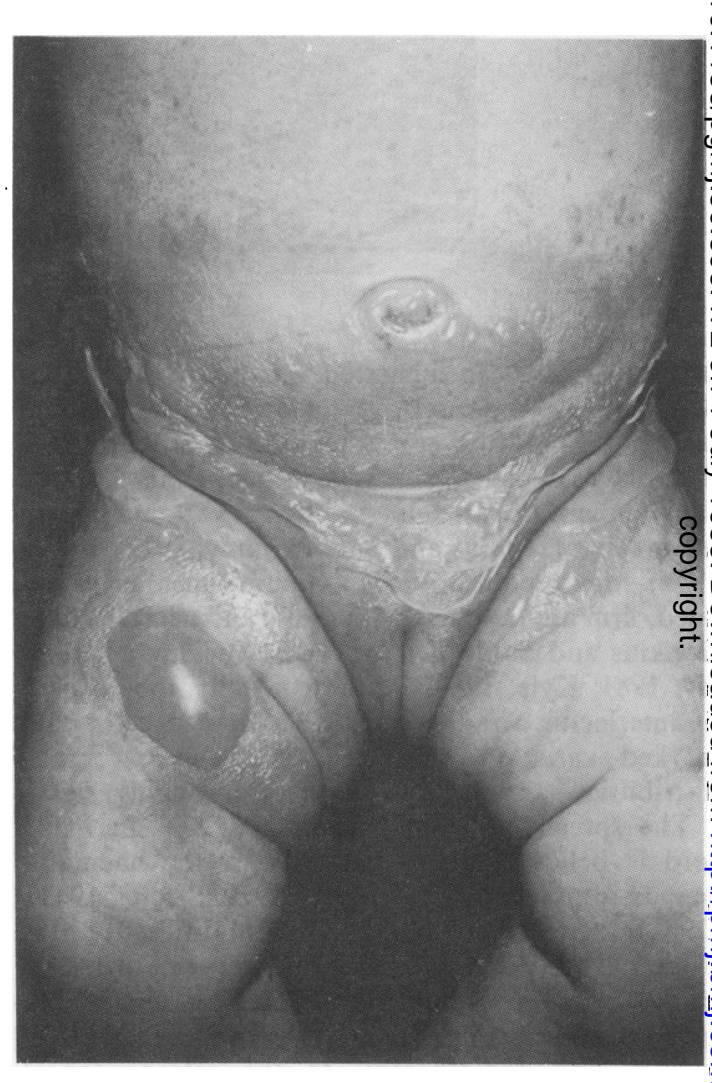

FIG. 1. Burns on admission.

There are several reports of adverse reactions to its topical use (Haidar, 1977; Sharvill, 1965), but chemi 0 cal burning is rare (August, 1975; Inman, 1982) N Occlusion seems to be important in causing necrosiso but the systemic toxic effects, which can be fatal, are only seen when the compound is ingested. There is no evidence that urine or any of its breakdown products react chemically with cetrimide.

A chemical burn of this nature has not previousle 


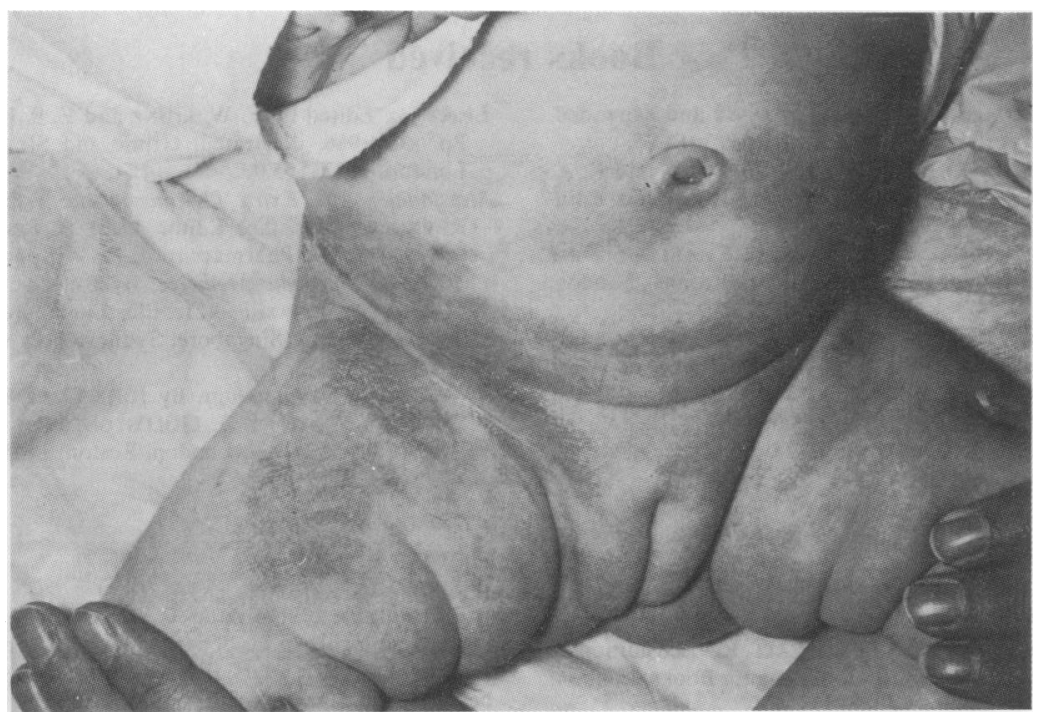

FIG. 2. After 7 days treatment with silver sulphadiazine cream.

been reported in a child of this age, despite the ready availability of this compound. Nonetheless, the possible toxic effects of cetrimide need to be more widely appreciated.

\section{Acknowledgment}

I wish to thank Mr J. Lendrum, Consultant Plastic Surgeon, for permission to report this case, and the Department of Medical Illustration for their help in preparing the illustrations.

\section{References}

August, P.J. (1975) Cutaneous necrosis due to cetrimide application. British Medical Journal, 1, 70.

HAIDAR, Z. (1977) An adverse reaction to a topical antiseptic (Cetrimide). British Journal of Oral Surgery, 15, 86.

INMAN, J. (1982) Cetrimide allergy presenting as suspected nonaccidental injury. British Medical Journal, 1, 284.

Pegg, S., Gregory, J., Hogan, G., Mottarelly, I. \& Walker, L. (1978) Burns in childhood: An epidemiological survey. Australian and New Zealand Journal of Surgery, 48, 365.

SharviLL, D. (1965) Reaction to chlorhexidine and cetrimide. Lancet, i, 771.

StitZ, R.W. (1972) Burns in children. A three-year survey. Medical Journal of Australia, 1, 357.

(Accepted 27 October 1982) 